\title{
How Childhood Maltreatment Links to Labor Values? The Mediating Role of Moral Competence and Prosocial Normative Tendency
}

\section{Yuliang Gu}

Hunan Normal University

Xiaomei Chao ( $\square$ chaoxm523@163.com )

Hunan Normal University

\section{Research Article}

Keywords: Childhood maltreatment, labor values, moral competence, prosocial normative tendency

Posted Date: February 15th, 2022

DOl: https://doi.org/10.21203/rs.3.rs-1295980/v1

License: (c) (i) This work is licensed under a Creative Commons Attribution 4.0 International License.

Read Full License 


\section{Abstract}

Background: Labor values are important for the individual value system. Especially in China, labor values are regarded as one of the most important values of an individual. In the study of values, childhood maltreatment is considered to have an important influence on the formation of individual values. However, previous studies have no research on the relationship between childhood maltreatment and labor values. The mechanism of childhood maltreatment on labor values is less understood but requires futher study.

Methods: This study intended to investigate the relationship between childhood maltreatment and labor values, and further to explore whether moral competence and prosocial normative tendency mediated this correlation. Therefore, 2691 participants were recruited from primary and secondary school, who completed Labor Values Scale, Childhood Trauma Questionnaire, Moral Competence subscale and Prosocial Norms subscale.

Results: Results revealed the negative correlation between childhood maltreatment and labor values. Importantly, childhood maltreatment also indirectly impacted labor values through moral competence and prosocial normative tendency. It indicated that both moral competence and prosocial normative tendency played a significant mediating role in this relationship. Our findings are valuable for understanding the underlying mechanism between early trauma and values.

Conclusions: Childhood maltreatment has important implications for labor values. Moral competence and prosocial normative tendency mediate between childhood maltreatment and labor values. This reminds us to pay attention to the important influence of childhood maltreatment in the cultivation of individual labor values. Also pay attention to the role of moral competence and prosocial normative tendency.

\section{Background}

Values refer to a preference tendency that meets people's needs, and are the conceptual system that guides people's cognitive judgment, choice, and behavioral practice (Roleach,1973; Schartz,1999; Huang and Zheng, 2015). On this basis, some scholars believe that labor values is an important part of the individual value system. It is people's general and fundamental views on the state and labor degree to meet people's needs, and it is the intrinsic needs of the individual and the labor characteristics or attributes pursued when engaging in activities (Guo and Liu, 2016). However, the existing research on the interpretation of the connotation of labor values is still very inadequate. On the one hand, there are very few studies on labor values; on the other hand, it is because Values have typical regional and cultural characteristics (Robinson,2008; Hartung, et al. , 2008). However, our department got some inspiration from the research on work values. For example, Super (1970) believes that work value is a criterion to judge work behavior and goals in a specific occupational field, and it is the basis for personal career choices. Some other researchers believe that work values can stably predict or explain internalized 
characteristics, behavioral expressions (Sortheix, et al. , 2015) or work motivation (Jambrak, et al. , 2014 ) in the corresponding work environment. There is a certain difference between the connotation of labor values and work values. According to the research of Hao (2014) and Tan (2019a, 2019b), labor values are an abstraction of all subjective evaluations of labor. In the Chinese institutional culture guided by Marxism, labor values have special meanings. According to the research of Tan (2019b), in Chinese culture, labor values refer to the individual's positive labor attitude, that is, refusing to be lazy, hurting others, self-interest and other negative values; at the same time, encouraging and cuitivate people to respect and enjoy the labor process and labor results, and to treat employees and labor results equally. Liu (2019) elaborated on the connotation of correct labor values from the perspective of labor education. He elaborated on the labor values that labor is great, laborers and labor results are worthy of respect. The Chinese official government has also discussed on many occasions what labor values should be established. For example, President Xi Jinping believes that positive labor values should be established with the main content of honest labor, equal labor, cherishing labor results, love of labor, and distribution of benefits according to labor(Xi,2014). The above connotations of labor values are also clearly explained in the research of Chao and Wang(Chao and Wang, 2020).

The nature of labor education is to cultivate correct labor values (Hu and Tan, 2018), which are determined by the choice and cognition that laborers show in the labor process ( $\mathrm{Yu}$ and $\mathrm{He}, 2014$ ). However, as society changes, The importance of labor education is increasingly being ignored. Some studies have found that more and more young people have no motivation to work, they are unwilling to work, and will not work(Chen, 2021). Our survey also found that many young people do not like hard work, and they prefer to choose jobs that are easy and easy to do. This is mainly because they did not cultivate healthy and positive labor values in the early stage. Therefore, it is particularly important to strengthen the education of youth labor values. However, in order to strengthen the education of young people's labor values, it is also necessary to know what factors may affect the young people's labor values. What factors need to be paid attention to in the education of youth labor values? How can we better provide youth education on labor values? These problems have not been effectively resolved. Our research is the first to link childhood maltreatment with adolescent labor values and discuss the impact of childhood maltreatment on adolescent labor values. It provides a theoretical and empirical reference for understanding the relationship between adolescents' early experiences and labor values. At the same time, our research lays a foundation for understanding the connotation of youth labor values under the background of the Chinese socialist system, as well as comparing the similarities and differences of youth labor values and influencing factors under different institutional and cultural backgrounds between China and Western countries.

We have noticed that under the influence of specific situations, values may change with age (Lönnqvist, et al. , 2018). There are also gender differences in labor values(Chao and Gu, 2021). At the same time, some studies have pointed out that there are differences in childhood maltreatment among adolescents of different genders and ages (Liao, et al. , 2011;Finkelhor, et al . ,2014). The above research inspires us, when discussing the impact of childhood maltreatment on labor values, it is necessary to pay attention to 
possible gender and age differences. According to our research, while analyzing the impact of childhood maltreatment on labor values, we will also verify and analyze the differences based on gender and age grouping.

\section{Introduction}

\subsection{Childhood maltreatment and labor values}

Childhood maltreatment refers to caregivers' actual or potential harmful behavior to children's physical and mental health(Kempe, 1984), including physical abuse, sexual abuse, emotional or psychological abuse and neglect(Bernstein, et al. , 1997). As an adverse experience in childhood, childhood maltreatment plays an enduring detrimental role in maltreated victims' physical and mental health(Fergusson, et al. , 2008). As suggested by literature, negative values might be one of the cognitive outcomes of childhood maltreatment(Smetana, et al. , 1984;Smetana, et al. , 1999). Values are preferences that meet people's needs, which form a conception system guiding people's cognitive judgment, choice and behaviors(Janik, et al. ,2021;Popovic, et al. ,2019). However, Magdalena (2013) has found that it is more difficult for maltreated children to get enough support from their social networks than non-maltreated ones, which hinders the development of positive values. Similarly, Catherine(2016) has also reported that maltreated adolescents are less likely to form friendly values because of deficits in social cognitive function. It can be concluded that childhood maltreatment is harmful for the formation of positive personal values. To our knowledge, no research has directly examined the relationship between childhood maltreatment and labor values, let alone the underlying mechanism. Investigating these issues is not only helpful for expanding knowledge about adverse experiences and negative consequences, but also valuable for reducing the enduring negative effect of this unchangeable adversity (i.e., childhood maltreatment) on shaping labor values practically. Therefore, the main aim of this study is to examine the relation between childhood maltreatment and labor values. In addition, we would further explore whether moral competence and prosocial normative tendency served as mediators in this correlation.

\subsection{The mediating role of moral competence}

The ability to judge the validity and rationality of certain social phenomena through cognitive control and moral judgment is called moral competence(Daniel, et al. , 2007). As a cognitive ability, moral competence may be undermined by unhealthy developmental environment. For instance, Zeng et al have suggested that individuals who grew up in maltreated environment are more likely to judge themselves negatively(Zeng, et al. , 2015). In addition to the biased judgment toward self-value, maltreated experience is also harmful for social cognition and might cause deficits in moral judgment(Yu, et al. , 2017; Catherine, et al. , 2016). Thus, childhood maltreatment is an environmental risk factor that might impair moral competence, which might further affect labor values. Though value is relative stable, it actually is an open and dynamic system that allowing change and adjustment(Huang, 2014). Identification ${ }^{19}$ and self-consistency maintenance(Arieli, et al. , 2014) are considered to contribute the change of values, both of which reflect moral judgement and evaluation to some degree. For example, 
self-identity and moral judgment are believed to impact the representation of values(Kaplan, et al. , 2016). Additionally, Mars et al(Mars, et al. , 2012). have found the formation and development of values may be accompanied by cognitive judgment and moral evaluation. These studies imply that the moral judgement and evaluation components of moral competence have potential impacts on values, and thus labor values are presumed to be affected by moral competence as well. Based on evidence shown before, it is hypothesized that childhood maltreatment weakens moral competence, through which further negatively influences the formation of positive labor values.

\subsection{The mediating role of prosocial normative tendency}

Prosocial normative tendency is the probability of persons' abidance by or being persuaded by social norms(Daniel, et al., 2012). Values are the core structure of socialization process(Li and He, 2013) that might be influenced by social norms' persuasion and social pressure(Hitlin and Piliavin, 2004). Pincus et al. (2014) have found that the formation and persistence of personal values can be impacted by the motivation to comply with "norms" in peer group. It is also believed that persuasion could prompt individuals to reevaluate their values and thus make the change of values possible(Falk and Scholz, 2018). Through persuasion, people can realize the unreasonable and absent aspects of original values and this provides an opportunity for shaping more positive values(Bardi, A., \& Goodwin, R., 2011; Falk, et al. , 2015). Therefore, those who have prosocial normative tendency have increased likelihood to form positive labor values because their tendency to follow and be changed by social norms. However, this desired tendency may be harmed by childhood maltreatment, which is an early traumatic and adverse experience. For example, Maughan et al. (2002) have found the majority of maltreated children have difficulty in regulating emotions, which makes them less likely to be accepted by peers and internalize social norms(Kim and Cicchetti, 2010). Previous studies have also demonstrated that people with a history of being maltreated have decreased possibility of observing social norms(Dittmer, et al. , 2011;Shipman, et al. , 2007). Therefore, we hypothesized that childhood maltreatment was detrimental for the formation of prosocial normative tendency, which in turn played a negative effect on labor values.

Based on the above evidence, this study focused on the impact of childhood maltreatment on labor values, and further intended to explore the mediating role of moral competence and prosocial normative tendency. Three research hypotheses of this paper were as followings. $\mathrm{H} 1$ : childhood maltreatment had a negative influence on labor values. $\mathrm{H} 2$ : childhood maltreatment negatively affects the individual's ability to distinguish right from wrong, which in turn affects the individual's formation of positive labor values. H3: childhood maltreatment hinders the individual from developing prosocial normative tendency, which in turn affects the individual's formation of positive labor values.

\section{Participants And Methods}

\subsection{Participants}

Participants were primary school children and adolescents from two primary schools, two junior high schools and one high school in Mainland China. 2691 valid questionnaires (1504 from boys and 1,187 
from girls) remained after deleting all the invalid questionnaires. The sample included the upper grades of elementary school (fourth, fifth, and sixth grade, 1303 participants), junior high school students (673 participants) and high school students (715 participants). The average age of this sample is $12.50 \pm$ 2.00. Ethics approval for this study was obtained from authors' organization.

\subsection{Measures}

\subsubsection{Labor Values Scale}

Labor Values Scale (LVS) developed by Chao and Wang ${ }^{15}$ basing on groups of senior primary school students aged 8-12 was employed to evaluate labor values. This scale consists of 15 items scored from 1 (totally disagree) to 5 (totally agree), including five dimensions (i.e., division value according to labor, honest, equal, cherishing and loving labor value). A sample item is "I enjoy the process of labor". Higher total scores indicate more positive labor values. At the same time, a study by Chao and $\mathrm{Gu}(2021)$ confirmed that the scale is also applicable to junior high school students and high school students aged 12-18. In our study, The Cronbach's a is 0.832 .

\subsubsection{Childhood Trauma Questionnaire}

Childhood Trauma Questionnaire (CTQ) designed by Bernstein et al.(2003) and revised by Nina He \& Yanhui Xiang(2021) was applied to evaluate the situation of childhood maltreatment in age 8-18. The CTQ includes 23 items rated on a 5-point scale ( 1 = never, 5 = always), and an example item is "My family threatened me in my childhood". This scale consists of physical abuse, physical neglect, emotional abuse and emotional neglect subscale. The Cronbach a coefficient of the whole scale is 0.898 .

\subsubsection{Moral Competence subscale and Prosocial Norms subscale}

The Clear and Positive Identity Subscale developed by Shek, Siu and Lee(2007) were adopted, which contained 15 subscales about the positive development of adolescents. Items of Moral Competence subscale (MC) and Prosocial Norms subscale (PN) were used to measure moral competence and prosocial normative tendency, respectively. Both of the two scales have three items. "I have high moral requirements for my behavior" is an example of MC and "I care about the unfortunate people in society" is an example of PN. All items were scored from 1 (strongly disagree) to 6 (strongly agree). The Cronbach a coefficients of $\mathrm{MC}$ and $\mathrm{PN}$ are 0.716 and 0.667 respectively.

\subsubsection{Data analysis}

Data analysis is divided into three steps: In the first step, we use Amos 20.0 to establish a measurement model to explore whether each observed variable can represent a latent variable; The second step is to construct a structural model. That is, early abuse as an independent variable, labor values as a dependent variable, and $\mathrm{MC}$ and $\mathrm{PN}$ as an intermediary to establish a full model; In the third step, we use bootstrap estimation procedure to detect the significance of the intermediary. According to a study by Byrne(2001), 
comparative fitting index (CFI), approximate root mean square error (RMSEA) and standardized root mean square residual (SRMR) were used as fitting indices to evaluate the model fitness.

\section{Results}

\subsection{Measurement model}

4 latent variables (i.e., labor values, moral competence, prosocial normative tendency and childhood maltreatment) and 15 observation variables are contained in the measurement model. The results have

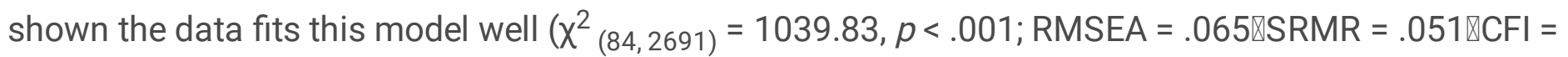
.926). And all latent variables are well represented by observed variables because the factor loads of all latent variables are significant $(p<.001)$. In addition, Table 1 has shown the correlations among four latent variables and demographic factors, and all latent variables are significantly correlated with each other.

Table 1 Descriptive statistics and bivariate correlations for all measures

\begin{tabular}{|llllllllll|}
\hline & $M$ & $S D$ & 1 & 2 & 3 & 4 & 5 & 6 & 7 \\
\hline 1. Gender & & & 1 & & & & & \\
\hline 2. Grade & & & .03 & 1 & & & & \\
\hline 3. Age & 12.50 & 2.00 & $.06^{\star \star}$ & $.91^{\star \star \star}$ & 1 & & & \\
\hline 4. Labor values & 59.03 & 8.65 & $-.06^{\star \star}$ & $-.16^{\star \star \star}$ & $-.17^{\star \star \star}$ & 1 & & \\
\hline 5. Moral competence & 13.42 & 2.87 & $-.07^{\star \star \star}$ & -.03 & $-.05^{\star}$ & $.49^{\star \star \star}$ & 1 & \\
\hline 6. PNT & 14.73 & 2.60 & $.11^{\star \star \star}$ & -.03 & $-.04^{\star}$ & $.53^{\star \star \star}$ & $.52^{\star \star \star}$ & 1 \\
\hline 7. CM & 32.87 & 11.89 & .02 & $-.15^{\star \star \star}$ & $-.15^{\star \star \star}$ & $-.23^{\star \star \star}$ & $-.16^{\star \star \star}$ & $-.21^{\star \star \star}$ & 1 \\
\hline
\end{tabular}

Note: PNT = Prosocial normative tendency; CM = Childhood maltreatment; ${ }^{*} p<.05,{ }^{\star *} p<.01,{ }^{* \star *} p<.001$

\subsection{Structural model}

Firstly, childhood maltreatment is related to labor values directly $(r=-.25, p<.001)$ when mediators are absent. Then a model with mediators of moral competence and prosocial normative tendency are has been built (Model 1). The fitting degree of this model is unsatisfactory: $\chi^{2}{ }_{(85,2691)}=1824.47, p<.001$; RMSEA $=.383 ;$ SRMR $=.106 ; \mathrm{CFI}=.865$. Therefore, we modified this model by linking errors of two mediators according to modification indices and theoretical relationships (Model 2, see Figure 1). The Model 2 has shown good fitness $\left(\chi^{2}(84,2691)=1039.83 \rrbracket p<.001 ; \mathrm{RMSEA}=.065 ; \mathrm{SRMR}=.051 ; \mathrm{CFI}=.926\right)$ and thus this model served as structural model in this study. 
Bootstrap estimation method (Bootstrap $=1000$ ) is further used to test whether the mediating paths are significant. And results indicates that childhood maltreatment indirectly impacts labor values through moral competence and prosocial normative tendency (see Table 2).

Table 2 Standardized indirect effect and 95\% confidence intervals

\begin{tabular}{|llll|}
\hline Paths & Estimate & Lower & Upper \\
\hline $\mathrm{CM} \rightarrow$ moral competence $\rightarrow$ labor values & -.09 & -.12 & -.06 \\
\hline $\mathrm{CM} \rightarrow \mathrm{PNT} \rightarrow$ labor values & -.12 & -.15 & -.08 \\
\hline
\end{tabular}

Note: The mediating effect of a pathway is significant if the $95 \%$ confidence interval does not include 0 .

\subsection{Gender differences}

We further examined the gender differences of structural model. Firstly, gender differences in every variable were tested. And results have shown boys score higher than girls in prosocial normative tendency and lower in moral competence and labor values, while there is no statistical difference in childhood maltreatment.

Secondly, gender differences in all path coefficients were tested by using multi-group analysis. After limiting the factor loadings, error variances and structural covariances to be equal, two models were established following Byrne(2001). The first one constrained all path coefficients in different gender to be equal (constrained structural paths) while the other did not (unconstrained structural paths). Both models fitted data well and they were not significantly different $\left(\triangle \chi^{2}(5,2691)=9.47, p \otimes .05\right)$. Since $\chi^{2}$ value could be affected by the sample size, critical ratios of differences (CRD) were also used to determine the crossgender stability of Model 2. Two parameters were considered different if the absolute value of CRD was greater than 1.96. And no path coefficients were different in different genders ( $C R D{ }_{C M \rightarrow M C}=-1.53 ; C R D$ $\left.\mathrm{MC} \rightarrow \mathrm{LV}=1.34 ; \mathrm{CRD}_{\mathrm{CM} \rightarrow \mathrm{LV}}=1.03 ; \mathrm{CRD}_{\mathrm{CM} \rightarrow \mathrm{PNT}}=-0.08 ; \mathrm{CRD}_{\mathrm{PNT} \rightarrow \mathrm{LV}}=-0.07\right)$. Based on these, there existed no significant gender difference in the structural model, indicating the cross-gender stability of this model.

\subsection{Grade differences}

We also tested the grade differences of structural model. First, we examined results in grade differences and found students in lower grades scored higher in childhood maltreatment and labor values, while no grade differences moral competence and prosocial normative tendency.

Then, grade differences in all path coefficients were also examined using multi-group analysis. Similar to the examination of gender differences, we limited the same parameters to be equal and then established two models (i.e., constrained structural paths and unconstrained structural paths). Though these models were significantly different $\left(\Delta \chi^{2}{ }_{(10,2691)}=21.74, p=.02\right)$, the results of CRD suggested that no path 
coefficients were different in different $\chi$ grades (primary school students vs. junior school students: CRD $\mathrm{CM} \rightarrow \mathrm{MC}=0.62 ; \mathrm{CRD}_{\mathrm{MC} \rightarrow \mathrm{LV}}=-0.94 \mathrm{CRD}_{\mathrm{CM} \rightarrow \mathrm{LV}}=-0.81 ; \mathrm{CRD}_{\mathrm{CM} \rightarrow \mathrm{PNT}}=1.31 ; \mathrm{CRD}_{\mathrm{PNT} \rightarrow \mathrm{LV}}=0.27 ;$ primary school students vs. high school students: $\mathrm{CRD}_{\mathrm{CM} \rightarrow \mathrm{MC}}=0.53 ; \mathrm{CRD}_{\mathrm{MC} \rightarrow \mathrm{LV}}=-1.46$; $_{\mathrm{CRD}}^{\mathrm{CM} \rightarrow \mathrm{LV}}=-0.63 ; \mathrm{CRD}$ $\mathrm{CM}_{\mathrm{P}} \mathrm{PNT}=0.89 ; \mathrm{CRD}_{\mathrm{PNT} \rightarrow \mathrm{LV}}=0.57$; junior school students vs. high school students: $\mathrm{CRD}_{\mathrm{CM} \rightarrow \mathrm{MC}}=-0.09$; $\mathrm{CRD}_{\mathrm{MC} \rightarrow \mathrm{LV}}=-0.49$ CRD $_{\mathrm{CM} \rightarrow \mathrm{LV}}=0.16$; $\left._{\mathrm{CRD}} \mathrm{CM} \rightarrow \mathrm{PNT}_{\mathrm{P}}=-0.27 \mathrm{CRD}_{\mathrm{PNT} \rightarrow \mathrm{LV}}=0.25\right)$. These results indicated there existed no significant grade difference in the structural model.

\section{Discussion}

The present research discussed the direct correlation between childhood maltreatment and children's labor values, and further explored whether moral competence and prosocial normative tendency mediated this relationship. Results revealed that childhood maltreatment was negatively correlated with labor values. In addition, childhood maltreatment indirectly affected labor values by moral competence and prosocial normative tendencies. These findings suggest that moral competence and prosocial normative tendency are pathways linking childhood maltreatment and labor values for the first time, providing theoretical guidance for reducing the influence of early traumatic experience on negative values from the perspective of cognitive ability and social tendency. In addition, our analysis results showed that the impact of childhood maltreatment on labor values did'nt not have significant differences between gender and grade groups on different paths. This showed that the results of the model analysis were consistent with a stable trend among different grades and genders.

Hypothesis 1 has been supported by the finding of the negative correlation between childhood maltreatment and labor values, which is similar with evidence that maltreated children are less likely to develop positive values( $\mathrm{Li}$, et al. , 2020). Education, especially family education from parents, is precisely an important factor in the formation of children's values(Sinnappan and Ahman, 2011; ). Childhood maltreatment puts children in an abnormal family education environment, which is detrimental to the cultivation of their labor values(Page, 1999). Therefore, it is difficult for children to form a positive selfevaluation and self-awareness in the unfavorable family environment of childhood maltreatment(Garber and Flynn, 2001), which hinders their normal interpersonal interaction(Hombrados, et al . , 2013). And negative interpersonal environment is detrimental to cultivate labor values. Therefore, childhood maltreatment is negatively related to labor values from the perspective of rational cognition and social interaction.

Interestingly, this study has found that moral competence is a mediator between childhood maltreatment and children's labor values, which supports hypothesis 2 . Existing studies have also reported that childhood maltreatment does harm to individuals' attitudes or behaviors through undermining their moral competence(Mills, et al . , 2013; Gini, et al . , 2014). Children who have experienced maltreatment usually have defects in social cognitive function and some prejudice in value judgment(Catherine, et al . , 2016). Insufficient ability in value judgment of maltreated children is reflected in low moral competence in this study, indicating that it is relatively more difficult for them to make reasonable moral judgments on social phenomenon. However, moral competence is important for cultivating children's labor values. The 
formation and development of values are series of process including concept judgment and decisionmaking(Mars, et al . , 2012), and the concept of right and wrong and moral competence are critical for shaping values. People with high cognitive control and moral judgment ability are more likely to keep positive and correct values and adhere to them(Aron, 2007; Carter and Veen, 2007). Conversely, people with poor moral competence have deficits in cognitive control and moral judgment, so they are less likely to form or maintain positive values. Therefore, people tend to have negative labor values if their moral competence is insufficient. In a word, childhood maltreatment undermines moral competence, which in turn makes it more difficult for people to form positive and normal labor values.

Similarly, the hypothesis 3 has also been confirmed that prosocial normative tendency mediates the correlation between childhood maltreatment and labor values. This may be because maltreated individuals are more prone to feel anger, and chronic anger further makes them more likely to engage in aggressive behavior and form antisocial personality(Trask, et al. , 2011), which are reflections of difficulties in accepting and abiding to social norms. Moreover, maltreated children are less likely to recognize and comply with social norms(Dittmer, et al . ,2011), which also suggests that childhood maltreatment experience is detrimental for developing prosocial normative tendency. However, this tendency plays an important role for people to accept persuasion from others, which further reduce the possibility of modifying inappropriate conceptions or developing positive ones. Values consist of systematic conceptions(Roleach, 1973; Schartz, 1999) and persuasion is a critical influencing factor of individual values(Vezich, et al. , 2017). It is believed that logical persuasion and restrictions of social norms can cultivate values by influencing cognitive process(Bardi and Goodwin, 2011). And the reason why social norms shapes values may be that conceptions are reevaluated and incorporated to existing value system(Falk, et al . , 2015). Based on above discussions, it can be understood that maltreated children have reduced probability of recognition and abidance to social norms (i.e., prosocial normative tendency), which further makes them tend to form negative labor values.

For various reasons, there are still some deficiencies in our research. Firstly, our respondents are from China. As a socialist country, the Chinese have attached great importance to the education of labor values since childhood. Compared with China, other countries may place very different emphasis on labor values education. Therefore, the relationship between childhood maltreatment and labor values in different countries needs further comparison. Secondly, labor values may change over time under the influence of labor behavior and labor education. But our study was not a longitudinal study. So it is impossible to determine how the impact of childhood maltreatment on labor values has changed over time. In the future, we will do a longitudinal study.

\section{Declarations}

\section{Ethics approval and consent to participate}

Human subjects' approval and all information was received by the University of Hunan Normal University Human Research Ethics Committee for the key informant interviews (ID: 20200725). Written informed 
consent was collected from all participants. It was emphasized that participation was voluntary. All methods were performed in accordance with the relevant guidelines.

\section{Consent for publication}

Participants were informed that the information they gave in the survey would be published in anonymised form.

\section{Competing interests}

The authors declare no competing interests.

\section{Funding}

Funding for this study came from The Hunan Women's Research Association as part of their Research programme on the Women's Research https://www.hnwomen.org.cn/2019/10/10/218576.html (Award ID: 19ZDB07). The design of the research is the sole responsibility of the authors. Feedback on the research outcomes was provided through discussions with a project advisory board at The Hunan Women's Research Association.

\section{Availability of data and materials}

The dataset used and analysed during the current study available from the corresponding author on reasonable request.

\section{Author Contributions}

All authors listed have made a substantial, direct and intellectual contribution to the work, and approved it for publication.

\section{Acknowledgements}

Not applicable.

\section{Reference}

1. Roleach, M. The nature of human values. New York $\square$ Free Press, 1973, 438.

2. Schartz, A. , H. A theory of cultural values and some implications for work. Applied Psychology, 1999, 48, 23-47. doi:10.1111/j.1464-0597.1999.tb00047.x

3. Huang, X. T. , Zheng, y. Introduction to Psychology. Beijing: People's Education Press, 2015. 207-210.

4. Guo, H. L. Liu, Y. The Origin, Connotation and Enlightenment of Deng Xiaoping's Labor Value. Mao Zedong Thought Study, 2016, 6: 48-53. 
5. Robinson, C. H., and Betz, N. E. A psychometric evaluation of super's work values inventory-revised. J. Career Assess, 2008, 16: 456-473. doi: 10.1177/1069072708318903

6. Hartung, P. J., Fouad, N. A., Leong, F. T. L., and Hardin, E. E. Individualism-collectivism: links to occupational plans and work values. J. Career Assess, 2010, 18: 34-45. doi: $10.1177 / 1069072709340526$

7. Super, D. E. Work Values Inventory. Boston, MA: Houghton Mifflin, 1970. doi: 10.1037/t01584-000

8. Sortheix, F. M., Chow, A., and Salmela-Aro, K. Work values and the transition to work life: a longitudinal study. J. Voc. Behav, 2015, 89, 162-171. doi: 10.1016/j.jvb.2015.06.001.

9. Jambrak, J., Deane, F. P., and Williams, V. Value motivations predict burnout and intentions to leave among mental health professionals. J. Ment. Health, 2014, 23: 120-124. doi: 10.3109/09638237.2013.869576.

10. Hao, Y. M. Survey and analysis of college students labor values and education strategy. Journal of Inner Mongolia University of Finance and Economics, 2014, 12: 98-101.

11. Tan,C.B. The development of labor education must solve three theoretical problems. People Educ. 2019. 17.

12. Tan, C. B. Understanding of the concept of labor education-how to understand the basic connotation and characteristics of the concept of labor education. J. Chin. Soc. Educ. 2019. 82-84.

13. Liu, X. L. To grasp the connotation of labor education comprehensively and accurately. Educ. Res. Exper, 2019, 4, 9-13.

14. Xi, J. P. The May Day celebration and the national congress to commend model workers and advanced workers was held. People Daily, 2015, 4, 29.

15. Chao, X., \& Wang, W. The Structure and Measurement of Labor Value in China Based on a Sample of Children Aged 8-12 Years. Frontiers in Psychology, 2020, 11. doi: 10.1016/S0145-2134(02)00541-0

16. Hu, J. J., and Tan, C. B. The Marxism View of Labor Values and Labor Education. Educ. Res, 2018, 460: 9-15.

17. Yu, L. R., and He, W. W. Study of the current situation of college students' labor values. J. Educ. Dev, 2014, 82: 222-248.

18. Chen, M. H. Engels' Research on Labor and Its Realistic Significance. Studies on Mao Zedong and Deng Xiaoping Theories, 2021, 1: 80-87.

19. Lönnqvist, J. E., Leikas, S., \& Verkasalo, M. Value change in men and women entering parenthood: New mothers' value priorities shift towards conservation values. Personality and Individual Differences, 2018, 120, 47-51. doi:10.1016/j.paid.2017.08.019

20. Xiaomei, C. , Yuliang, G. Effects of Labor Values on Subjective Well-Being: The Mediating Role of Altruistic Tendencies. Frontiers in Psychology. doi.org/10.3389/fpsyg. 2021.715179

21. Liao, M. , Lee, A. S. , AC Roberts-Lewis, Hong, J. S. , \& Jiao, K. Child maltreatment in china: an ecological review of the literature. Children and Youth Services Review, 2011, 33: 1709-1719. doi: 10.1016/j.childyouth.2011.04.031 
22. Finkelhor, D. , Vanderminden, J. , Turner, H. , Hamby, S. , Shattuck, A. Child maltreatment rates assessed in a national household survey of caregivers and youth. Child Abuse and Neglect, 2014, 38, 1421-1435. doi:10.1016/j.chiabu.2014.05.005

23. Kempe, C. H. The battered-child syndrome. JAMA The Journal of the American Medical Association, 1984, 24: 3288. doi: 10.1001/jama.1984.03340480070033

24. Bernstein, D. P., Ahluvalia, T., Pogge, D., \& Handelsman, L. Validity of the childhood trauma questionnaire in an adolescent psychiatric population. Journal of the American Academy of Child \& Adolescent Psychiatry, 1997, 36: 340-348. doi: 10.1097/00004583-199703000-00012

25. Fergusson, D. M. Boden, J .M. Horwood, L. J. Exposure to childhood sexual and physical abuse and adjustment in early adulthood. Child Abuse and Neglect, 2008, 32: 607-619.

26. Smetana, J. G. , Kelly, M. , \& Twentyman, C. T. Abused, neglected, and nonmaltreated children's conceptions of moral and social-conventional transgressions. Child Development, 1984, 55: 277-287. doi:10.1111/j.1467-8624.1984.tb00291.x

27. Smetana, J. G. , Toth, S. L. , Cicchetti, D. , Bruce, J. , Kane, P. , \& Daddis, C. Maltreated and nonmaltreated preschoolers' conceptions of hypothetical and actual moral transgressions. Developmental Psychology, 1999, 35: 269-281. doi:10.1037/0012-1649.35.1.269

28. Janik. Goltermann, Redlich, R. , Grotegerd, D. , Dohm, K. , \& U Dannlowski. Childhood maltreatment and cognitive functioning: the role of depression, parental education, and polygenic predisposition. Neuropsychopharmacology, 2021, 46: 891-899. doi:10.1038/s41386-020-00794-6

29. Popovic, D. , Schmitt, A. , Kaurani, L. , Senner, F. , Papiol, S. , \& Malchow, B. , A. Fischer, TG Schulze, N. Koutsouleris, P. Falkai. Childhood trauma in schizophrenia: current findings and research perspectives. Frontiers in Neuroscience, 2019, 13. doi:10.3389/fnins.2019.00274

30. Magdalena, V. D. W. J. Exploring factors that contribute to prosocial behaviour of maltreated adolescent females living in residential care/johanna magdalena van der walt. Adolescent Female, 2013.

31. Catherine, L. , Kay, Jonathan, M. , Green. Social cognitive deficits and biases in maltreated adolescents in U.K. out-of-home care: Relation to dis-inhibited attachment disorder and psychopathology. Development and Psychopathology, 2016, 28: 73-83. doi:

$10.1017 /$ S0954579415000292

32. Daniel T. L. Shek, Andrew M. H. Siu. , Tak, Yan, Lee. The Chinese Positive Youth Development Scale: A Validation Study. Research on Social Work Practice, 2007, 17: 380-393. doi: 10.1007/978-94-0070753-5_3557

33. Zeng, Q. W. , Liu, A. S. , \& Li, S. Y. The Relationship between Childhood Psychological Maltreatment and Trait Depression:a Chain Mediating Effect of Rumination and Post-traumatic Cognitive Changes. Chinese Journal of Clinical Psychology, 2015, 23: 665-669. doi: 10.16128/j.cnki.10053611.2015.04.022

34. Yu. Z. Y. , Zhao, A. M. , Liu, A. S. A meta-analysis of childhood abuse and depression. Acta Psychologica Sinica, 2017, 49: 40-49. doi:10.3724/SP.J.1041.2017.00040 
35. Huang, X. T. Explore the mystery of personality. Beijing: Business Press, 2014.

36. Arieli, S. , Grant, A. M. , \& Sagiv, L. Convincing yourself to care about others: an intervention for enhancing benevolence values. J Pers, 2014, 82: 15-24. doi: 10.1111/jopy.12029

37. Kaplan, J. T., Gimbel, S. I., Dehghani, M., Immordino-Yang, M. H., Sagae, K., Wong, J. D.,

38. 38.Damasio, A. Processing narratives concerning protected values: A cross-cultural investigation of neural correlates. Cerebral Cortex, 2016, 27: 1428-1438. doi: 10.1093/cercor/bhv325

39. Mars, R. B., Sallet, J., Schüffelgen, U., Jbabdi, S., Toni, I., \& Rushworth, M. F. Connectivity-based subdivisions of the human right "temporoparietal junction area": Evidence for different areas participating in different cortical networks. Cerebral Cortex, 2012, 22: 1894-1903. doi: $10.1093 / \mathrm{cs} / 23.2 .85$

40. Lin, L. , Xiting, H. A Review of Thrifty Psychology Research. Psychology and the Improvement of Innovation Ability-Proceedings of the 16th National Conference on Psychology, Nanjing, 2013, 569571.

41. Hitlin, S., \& Piliavin, J. A. Values: Reviving a dormant concept. Annual Review of Sociology, 2004, 30: 359-393. doi: 10.1146/annurev.soc.30.012703.110640

42. Vezich, I. S., Katzman, P. L., Ames, D. L., Falk, E. B., \& Lieberman, M. D. Modulating the neural bases of persuasion: Why/how, gain/loss, and users/non-users. Social Cognitive and Affective Neuroscience, 2017, 12: 283-297. doi:10.1093/scan/nsw113

43. Pincus, M., LaViers, L., Prietula, M. J., \& Berns, G. The conforming brain and deontological resolve. PloS one, 2014, 9(8), e106061. doi:10.1371/journal.pone.0106061

44. Falk, E., \& Scholz, C. Persuasion, influence, and value: Perspectives from communication and social neuroscience. Annual Review of Psychology, 2018, 69: 329-356. doi: 10.1146/annurev-psych122216-011821

45. Bardi, A., \& Goodwin, R. The dual route to value change: Individual processes and cultural moderators. Journal of Cross-cultural Psychology, 2011, 42: 271-287. doi: $10.1177 / 0022022110396916$

46. Falk, E. B., O'Donnell, M. B., Cascio, C. N., Tinney, F., Kang, Y., Lieberman, M. D., Strecher, V. J. Selfaffirmation alters the brain's response to health messages and subsequent behavior change. Proceedings of the National Academy of Sciences, 2015, 112: 1977-1982. doi: 10.1073/pnas. 1500247112

47. Maughan, A. , Cicchetti, D. Impact of child maltreatment and interadult violence on children's emotion regula- tion abilities and socioemotional adjustment. Child Development, 2002, 73: 1525-1542. doi: $10.1111 / 1467-8624.00488$

48. Kim, J. , \& Cicchetti, D. Longitudinal pathways linking child maltreatment, emotion regulation, peer relations, and psychopathology. J Child Psychol Psychiatry, 2010, 51: 706-716. doi: 10.1111/j.14697610.2009.02202.x

49. Dittmer M, Hubel G, Hansen DJ. Factors Associated with Participation and Retention in a Group Treatment for Child Sexual Abuse. The McNair Scholars Research Journal, 2011, 27, 745-52. doi: 
10.1016/j.ejcts.2005.02.007

50. Shipman. K. L. , Schneider. R. , Fitzgerald, M. M. Maternal emotion socialization in maltreating and non-maltreating families: Implications for children's emotion regulation. Social Development, 2007, 16: 268-285. doi:10.1111/j.1467-9507.2007.00384.x

51. A, David P Bernstein. "Development and validation of a brief screening version of the Childhood Trauma Questionnaire. "Child Abuse \& Neglect, 2003, 27: 169-190. doi: 10.1016/S01452134(02)00541-0

52. Nina, H. , Xiang, Y. H. How child maltreatment impacts internalized/externalized aggression among Chinese adolescents from perspectives of social comparison and the general aggression model. Child Abuse \& Neglect, 2021, 117. doi: 10.1016/j.chiabu.2021.105024

53. Byrne, B. M. Structural equation modeling with AMOS, EQS, and LISREL: Comparative approaches to testing for the factorial validity of a measuring instrument. International Journal of Testing, 2001, 1: 55-86. doi: 10.1207/S15327574IJT0101_4

54. Arbuckle, J. L. AMOS 5.0 update to the AMOS user's guide. Chicago, IL: Smallwaters, 2003.

55. Li, Y. J. Yu, B. Han, J. Y. Yang S. F. Dai, Z. Wu, S. R. Fan, S. F. Analysis of the Status Quo and Influencing Factors of College Students' Sexual Values in Chengdu. Practical Preventive Medicine, 2020, 27: 1311-1315.

56. Sinnappan, P. R. , Ahman, A. Antecedents of green purchasing behavior among Malaysian consumers. International Business Management, 2011, 5: 129-139. doi:10.3923/ibm.2011.129.139

57. Page, T. The attachment partnership as conceptual base for exploring the impact of child maltreatment. Child \& Adolescent Social Work Journal, 1999, 16: 419-437. doi: 10.1023/A:1022397204929

58. Garber, J., \& Flynn, C. Predictors of depressive cognition in young adolescents. Cognitive Therapy and Research, 2001, 4: 353-376. doi: 10.1023/A:1005530402239

59. Hombrados, Mendieta, I., García-Martín, M. A., \& Gómez-Jacinto, L. The relationship between social support, loneliness, and subjective well-being in a Spanish sample from a multidimensional perspective. Social Indicators Research, 2013, 114: 1013-1034. doi: 10.1007/s11205-012-0187-5

60. Mills, R., Scott, J., Alati, R. Child maltreatment and adolescent mental health problems in a large birth cohort. Child Abuse \& Neglect, 2013, 37: 292-302. doi: 10.1016/j.chiabu.2012.11.008

61. Gini, G., Pozzoli, T., Vieno, A., \ Lenzi, M. Bullying victimization at school and headache: A metaanalysis of observational studies. Headache: The Journal of Head and Face Pain, 2014, 54: 976-986. doi: 10.1111/head.12344

62. Aron, A. R. The neural basis of inhibition in cognitive control. The Neuroscientist, 2007, 13: 214-228. doi: $10.1177 / 1073858407299288$

63. Carter, C. S., \& van Veen, V. Anterior cingulate cortex and conflict detection: An update of theory and data. Cognitive, Affective, \& Behavioral Neuroscience, 2007, 7: 367-379. doi: 10.3758/CABN.7.4.367 
64. Trask, E. V. , Walsh, K. , Di, Lillo, D. Treatment effects for common outcomes of child sexual abuse: A current me-ta-analysis. Aggression and Violent Behavior, 2011, 16: 6-19. doi:10.1016/j.avb.2010.10.001

\section{Figures}

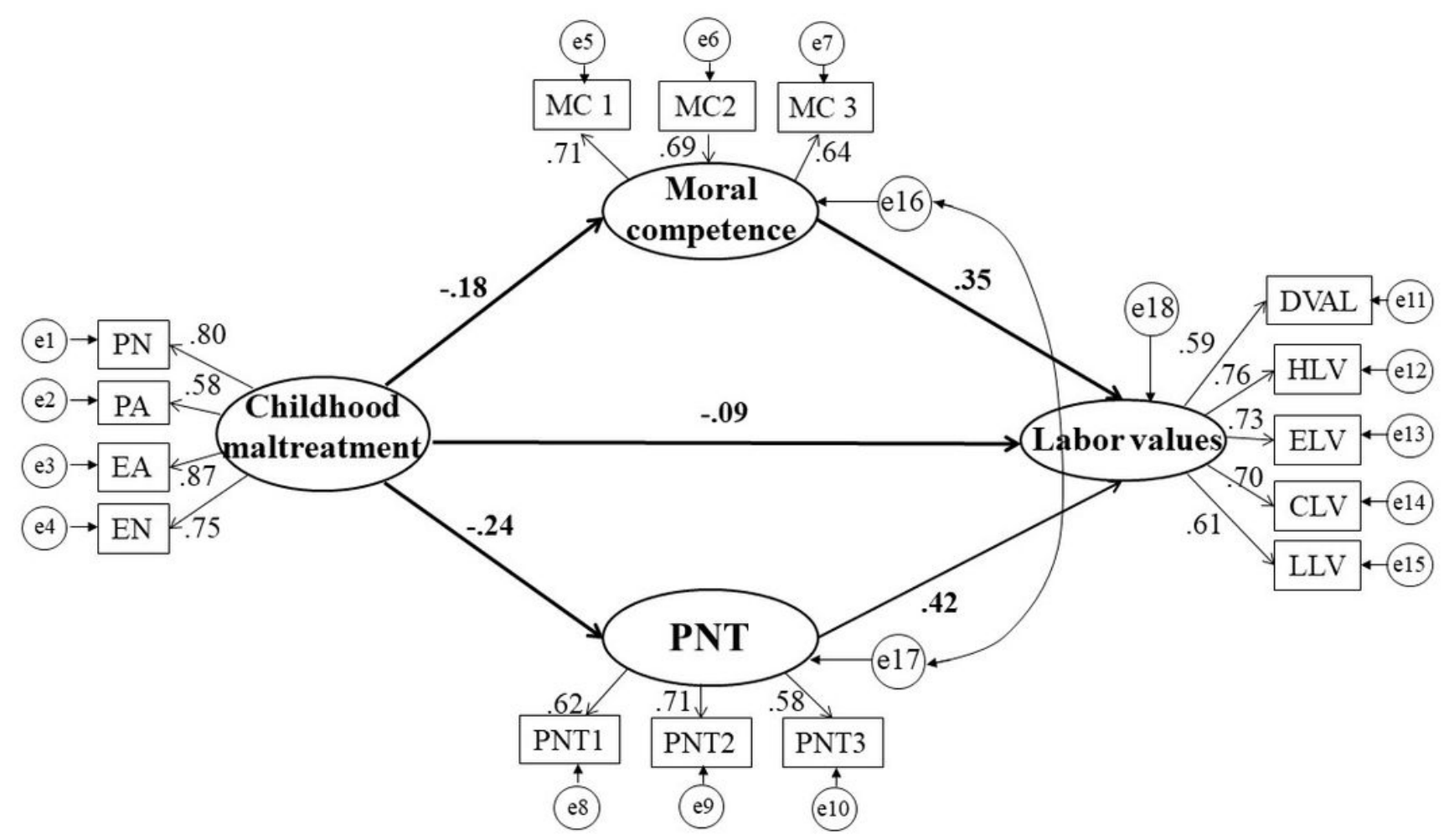

\section{Figure 1}

Structural model $(\mathrm{N}=2691)$

Note: All path coefficients are significant at the level of .001. PNT = Prosocial normative tendency; CM = Childhood maltreatment. PA, PN, EA and EN represents physical abuse, physical neglect, emotional abuse and emotional neglect. DVAL, HLV, ELV, CLV and LLV represents division value according to labor, honest labor value, equal labor value, cherishing labor value and loving labor value. MC1, MC2, MC3 are items of Moral Competence subscale (MC) and PNT1, PNT2, PNT3 are items of Prosocial Norms subscale. 